\title{
A Straightforward Convergence Method for ICCG Simulation of Multiloop and Time-Stepping FE Model of Synchronous Generators with Simultaneous AC and Rectified DC Connections
}

\author{
Shanming Wang, Ziguo Huang, Shujun Mu, and Xiangheng Wang \\ State Key Laboratory of Control and Simulation of Power System and Generation Equipments, Department of Electrical Engineering, \\ Tsinghua University, Beijing 100084, China \\ Correspondence should be addressed to Shanming Wang; wangsm96@mails.tsinghua.edu.cn
}

Received 4 August 2014; Accepted 4 October 2014

Academic Editor: Song Cen

Copyright (C) 2015 Shanming Wang et al. This is an open access article distributed under the Creative Commons Attribution License, which permits unrestricted use, distribution, and reproduction in any medium, provided the original work is properly cited.

\begin{abstract}
Now electric machines integrate with power electronics to form inseparable systems in lots of applications for high performance. For such systems, two kinds of nonlinearities, the magnetic nonlinearity of iron core and the circuit nonlinearity caused by power electronics devices, coexist at the same time, which makes simulation time-consuming. In this paper, the multiloop model combined with FE model of AC-DC synchronous generators, as one example of electric machine with power electronics system, is set up. FE method is applied for magnetic nonlinearity and variable-step variable-topology simulation method is applied for circuit nonlinearity. In order to improve the simulation speed, the incomplete Cholesky conjugate gradient (ICCG) method is used to solve the state equation. However, when power electronics device switches off, the convergence difficulty occurs. So a straightforward approach to achieve convergence of simulation is proposed. At last, the simulation results are compared with the experiments.
\end{abstract}

\section{Introduction}

Now power electronics are widely used with electrical machines together, not only with motors, but also with generators. Power electronics promotes great flexibility of electrical machine control, but at the same time fast and frequent switching of power electronics devices causes some problems, such as harmonics. So the detailed research on the system of electrical machine and power electronics is necessary.

For systems of electrical machine and power electronics, two nonlinearities coexist at the same time, which make analysis difficult and simulation time-consuming: the magnetic nonlinearity of iron core and the circuit nonlinearity caused by power electronics devices. Two effective ways to analyze and simulate such complex systems are finite element method for magnetic nonlinearity and variable-step variabletopology simulation for circuit nonlinearity. Now the circuit model combined with FE model is effective and popular for detailed analysis of such systems [1-5]. But because of the nonlinear characteristic of magnetic circuit of electrical machines, one iteration inside every time step is needed and the simulation is time-consuming. If the power electronics devices were involved, the situation would be worsened further.

In order to improve the simulation speed, the incomplete Cholesky conjugate gradient (ICCG) method is used to solve the state equation [6-8]. However, when power electronics device switches off, the convergence difficulty occurs $[7,8]$. So a straightforward approach to achieve convergence of simulation is proposed in this paper. The simulation results obtained by the proposed method are compared with the experiments. The AC-DC synchronous generator $[9,10]$ including four rectifier bridges [11] is used as an example, as shown in Figure 1. There are five independent 3-phase Y-windings in the AC-DC generator: the one called AC winding supplies AC power and the others, DC windings, are connected to four three-phase rectifier bridges and supply DC power. The diode switching of four three-phase rectifier bridges makes the topology of circuit change periodically and frequently. 


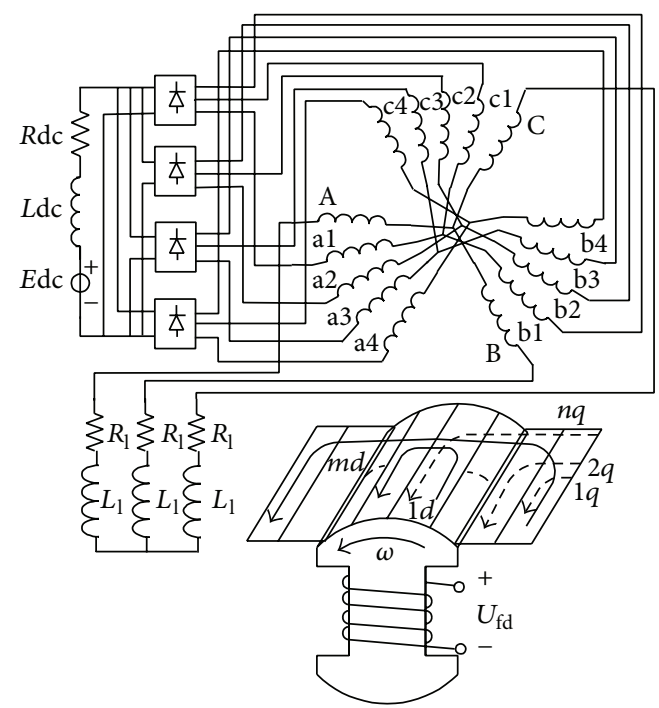

FIgURE 1: The AC-DC generator under investigation.

\section{Mathematic Model}

2.1. Multiloop Model of Generators. For multiloop model, each winding is regarded as a circuit element, as is each shortcircuited loop in the damper cage. The motor convention is applied to the rotor loops, while applying the generator system for the stator loops. The multiloop voltage equations of the generator can be expressed in a compact matrix form:

$$
\mathbf{U}_{\mathrm{F}}=-\mathbf{L}_{\mathbf{L}} p \mathbf{I}_{\mathrm{F}}-p \Psi_{\mathrm{M}}-\mathbf{R}_{\mathrm{F}} \mathbf{I}_{\mathrm{F}}
$$

where the differential operator $p=d / d t ; \mathbf{U}_{\mathrm{F}}, \mathbf{I}_{\mathrm{F}}$ are the voltage and current vector, respectively, including the field winding, damper winding, three-phase AC winding, and four three-phase DC windings; $\mathbf{R}_{\mathrm{F}}$ is the resistance matrix; $\Psi_{\mathrm{M}}$ is the flux linkage which is related to the saturation of iron core and should be calculated by FE model; and $\mathrm{L}_{\mathrm{L}}$ is the end winding leakage inductance matrix which is not related to the saturation of iron core.

2.2. FE Model of Generators. The FE model of generators can be expressed as

$$
\mathbf{S} \cdot \mathbf{A}_{\mathrm{F}}=\mathbf{C} \cdot \mathbf{I}_{\mathrm{F}}
$$

where $\mathbf{A}_{\mathrm{F}}$ is the unknown vector of vector potentials of nodes, $\mathbf{S}$ is the coefficient matrix formed by the element analysis of FEM, and $\mathbf{C}$ is the connection matrix representing the relationships between the currents and the nodes.

The $\boldsymbol{\Psi}_{\mathrm{M}}$ in (1) is $\boldsymbol{\Psi}_{\mathrm{M}}=2 P l_{\mathrm{ef}} \mathbf{C}^{\mathrm{T}} \cdot \mathbf{A}_{\mathrm{F}}$, where $P$ is pole pair number and $l_{\mathrm{ef}}$ is the length of iron core.

\subsection{Load Model. Consider the following:}

$$
\mathbf{U}_{1}-\mathbf{E}_{1}=\mathbf{L}_{1} \frac{d \mathbf{I}_{1}}{d t}+\mathbf{R}_{1} \mathbf{I}_{1}
$$

where $\mathbf{U}_{1}, \mathbf{E}_{l}$, and $\mathbf{I}_{1}$ are the voltage, emf, and current vector of AC load and DC load, respectively, and $\mathbf{L}_{1}$ and $\mathbf{R}_{1}$ are the inductance matrix and resistance matrix of load, respectively.
2.4. System Model. By combining the equations of generator (1) with load (3), a system circuit equation is gotten as follows:

$$
\mathbf{U}=-\mathbf{L} p \mathbf{I}-p \Psi-\mathbf{R I}
$$

where, in the $\mathbf{R}, \mathbf{L}$ and $\mathbf{I}, \mathbf{U}, \boldsymbol{\Psi}$, the quantities associating with the AC and DC loads are appended.

After combination of (4) and (2) and discretization, the system model can be obtained as

$$
\begin{aligned}
& {\left[\begin{array}{cc}
\mathbf{S} & \mathbf{C}^{\prime} \\
\mathbf{C}^{\prime \mathrm{T}} & -\frac{\Delta t \cdot \mathbf{R}}{4 P l_{\mathrm{ef}}}-\frac{\mathbf{L}}{2 P l_{\mathrm{ef}}}
\end{array}\right]\left[\begin{array}{c}
\mathbf{A}_{n+1} \\
-\mathbf{I}_{n+1}
\end{array}\right]} \\
& =\left[\begin{array}{cc}
\mathbf{0} & \mathbf{0} \\
\mathbf{C}^{\prime \mathrm{T}} & -\frac{\Delta t \cdot \mathbf{R}}{4 P l_{\mathrm{ef}}}+\frac{\mathbf{L}}{2 P l_{\mathrm{ef}}}
\end{array}\right]\left[\begin{array}{l}
\mathbf{A}_{n} \\
\mathbf{I}_{n}
\end{array}\right]+\left[\begin{array}{c}
\mathbf{0} \\
-\frac{\Delta t \cdot \mathbf{U}_{n}}{2 P l_{\mathrm{ef}}}
\end{array}\right],
\end{aligned}
$$

where $\mathbf{C}^{\prime}$ also includes the elements associating with the AC and DC loads and $\Delta t$ is the simulation step. The subscript $n$ represents the time instant, while $n+1$ represents the instant one step $\Delta t$ later.

\section{Connection Transformation}

Equation (5) is only the model of circuit branches and elements of FEM, not the actual loops, and cannot be solved directly. So a connection transformation is needed to form an independent loop model, decided by the operating load condition and the state of diodes. The connection can be represented by a connection transformation matrix T. The connection transformation matrix is important and convenient for the simulation of electric machine and power electronics system. It should be noted that once a power electronics device, such as a diode in this paper, switches on or off, the connection transformation matrix $\mathbf{T}$ must be redetermined to represent the variable topology.

After founding the connection transformation matrix, the voltages and currents can be transformed as $\mathbf{U}^{\prime}=\mathbf{T U}, \mathbf{I}=$ $\mathbf{T}^{\mathrm{T}} \mathbf{I}^{\prime}$. Then, the actual equation can be expressed as

$$
\begin{aligned}
& {\left[\begin{array}{cc}
\mathbf{S} & \mathbf{C}^{\prime} \mathbf{T}^{\mathbf{T}} \\
\mathbf{T C}^{\prime \mathrm{T}} & \mathbf{T}\left(-\frac{\Delta t \cdot \mathbf{R}}{4 P l_{\mathrm{ef}}}-\frac{\mathbf{L}}{2 P l_{\mathrm{ef}}}\right) \mathbf{T}^{\mathbf{T}}
\end{array}\right]\left[\begin{array}{c}
\mathbf{A}_{n+1} \\
-\mathbf{I}_{n+1}^{\prime}
\end{array}\right]} \\
& =\left[\begin{array}{c}
\mathbf{0} \\
\mathbf{T} \mathbf{C}^{\prime \mathrm{T}} \mathbf{T}\left(-\frac{\Delta t \cdot \mathbf{R}}{4 P l_{\mathrm{ef}}}+\frac{\mathbf{L}}{2 P l_{\mathrm{ef}}}\right) \mathbf{T}^{\mathbf{T}}
\end{array}\right]\left[\begin{array}{c}
\mathbf{A}_{n} \\
\mathbf{I}_{n}^{\prime}
\end{array}\right] \\
& +\left[\begin{array}{c}
\mathbf{0} \\
\mathbf{T}\left(-\frac{\Delta t \cdot \mathbf{U}_{n}}{2 P l_{\mathrm{ef}}}\right)
\end{array}\right] .
\end{aligned}
$$

The multiloop model and FE model are assembled into one equation so that it eliminates the iteration between these two models while they are solved separately. 


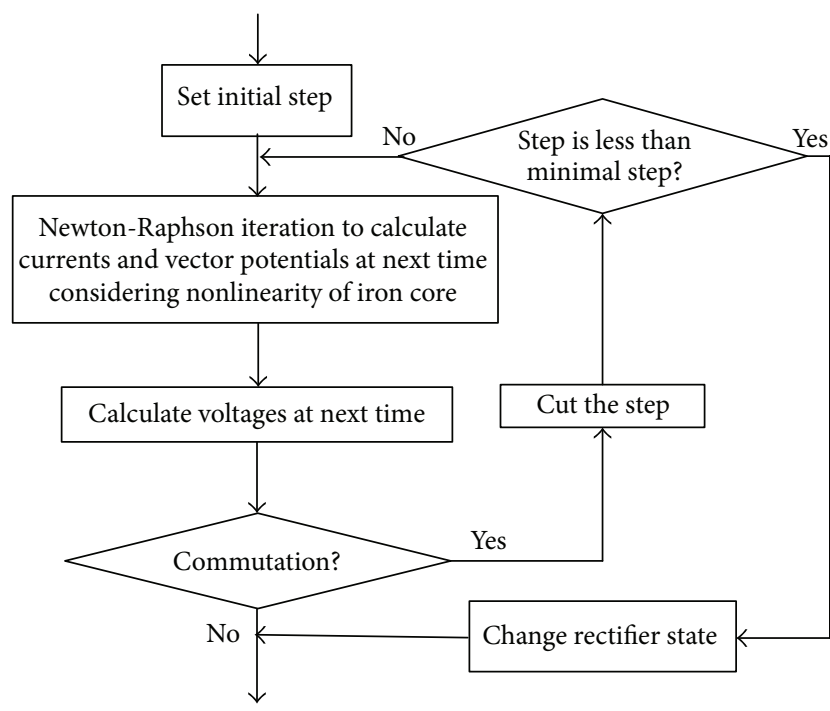

FIGURE 2: Flowchart of two iterations of simulation.

After carrying out magnetic field computation by Newton-Raphson method one time using the initial currents, the initial vector potential $\mathbf{A}_{n}$ is known and the iteration process can be time-stepped forward by (6).

\section{Difficulties of Simulation}

The AC-DC generator with rectifier is a typical system comprising of electric machines and power electronics. It has some distinct characteristics which imply the difficulties of simulation.

4.1. Two Types of Nonlinearities. There are two kinds of nonlinearities coexisting in the AC-DC generator: one is the magnetic circuit nonlinearity of iron core and the other is the electric circuit nonlinearity caused by power electronics devices.

4.2. Uncontrolled Rectifier. The four three-phase DC windings of AC-DC generators are connected to the four threephase diode rectifiers. The power electronics device is diode, whose switching action is uncontrolled. When the voltage between the terminals of diode is positive, then the diode switches on. While the current that flows through the diode changes from positive to negative and the terminal voltage of diode is negative, the diode switches off. That means that the switching action of diode is decided by the voltage and current, which cannot be known before the voltage and current are calculated for one given instant.

Two kinds of iterations are applied to solve these two difficulties, as shown in Figure 2.

(1) Because of the nonlinear characteristic of the magnetic material, Newton-Raphson iteration method is used to solve the nonlinear equation (6) and calculate the currents and vector potentials. The right side vector of equation is formed only one time in every step, while the Jacobi matrix of left side must be modified during every iteration.
TABLE 1: Comparison of calculation time of different steps by Gauss elimination method and ICCG method.

\begin{tabular}{lccc}
\hline Step number & $\begin{array}{c}\text { Iteration } \\
\text { times }\end{array}$ & $\begin{array}{c}\text { Gauss } \\
\text { elimination } \\
\text { method (s) }\end{array}$ & $\begin{array}{c}\text { ICCG } \\
\text { method (s) }\end{array}$ \\
\hline 1 & 6 & 1.047 & 0.719 \\
2 & 5 & 0.828 & 0.578 \\
3 & 6 & 1.031 & 0.672 \\
4 & 5 & 0.813 & 0.547 \\
5 & 6 & 1.000 & 0.703 \\
6 & 5 & 0.813 & 0.562 \\
7 & 5 & 0.813 & 0.562 \\
8 & 5 & 0.812 & 0.563 \\
9 & 5 & 0.813 & 0.594 \\
10 & 5 & 0.797 & 0.531 \\
\hline
\end{tabular}

(2) In order to find out the commutation instant accurately, the variable-step simulation method is used to solve (6).

As shown in Figure 2, if there is no commutation within the next step, simulation steps forward keeping the current step. If a commutation occurs within the next step, the step is cut in half until that step reaches the minimal step or no commutation occurs inside the current step. The minimal step is determined by the speed and precision of simulation. From the process and results of simulation, the minimal step is set as $1 e^{-6} \mathrm{~s}$ which can reach the good compromise of speed and precision.

Because of the switching action of the rectifier, the topology of the generator and loads changes repetitively. While a switching action takes place, only the elements in the matrix $\mathbf{T}$ need to be modified.

\section{Comparison between ICCG Method and Gauss Elimination Method}

Originally, Gauss elimination method is used to solve the state equation; the process goes smoothly and the results are consistent with the experiments [11]. But because of magnetic nonlinearity of iron core and the circuit nonlinearity of diode, two iterations are included: Newton-Raphson iteration and variable-step iteration. So the simulation process is very timeconsuming.

To shorten the simulation time, as in many published literatures, the ICCG method is used for solution of the state equations. Table 1 shows the comparison of calculation time of Gauss elimination method and ICCG method for the same series of steps under working condition with only AC load and without DC load, which means that the topology of circuit is not changed. From Table 1, it can be seen that the iteration times are the same for different steps by these two methods, but total time for different steps is different and the calculation time of ICCG method is shorter than Gauss elimination method; that is, the speed of ICCG method is greater than that of Gauss elimination method. When the 


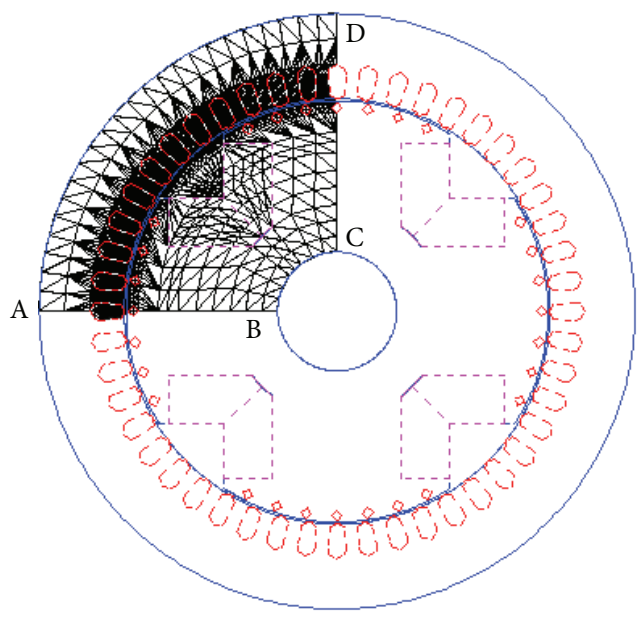

(a) Section view and mesh

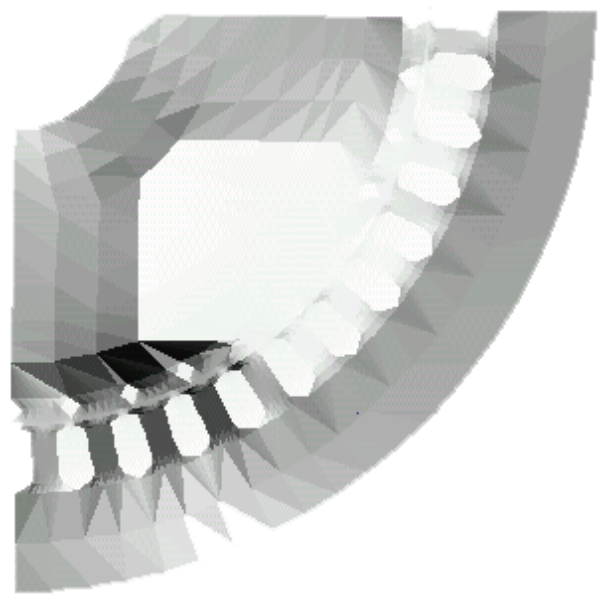

(b) Flux density picture

FIgURE 3: Section view and mesh and flux density picture.

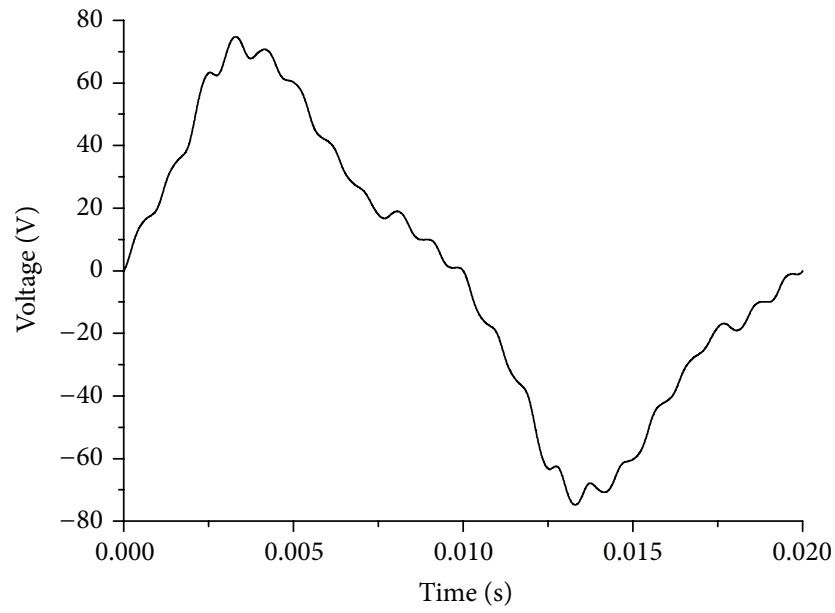

(a) Calculated result

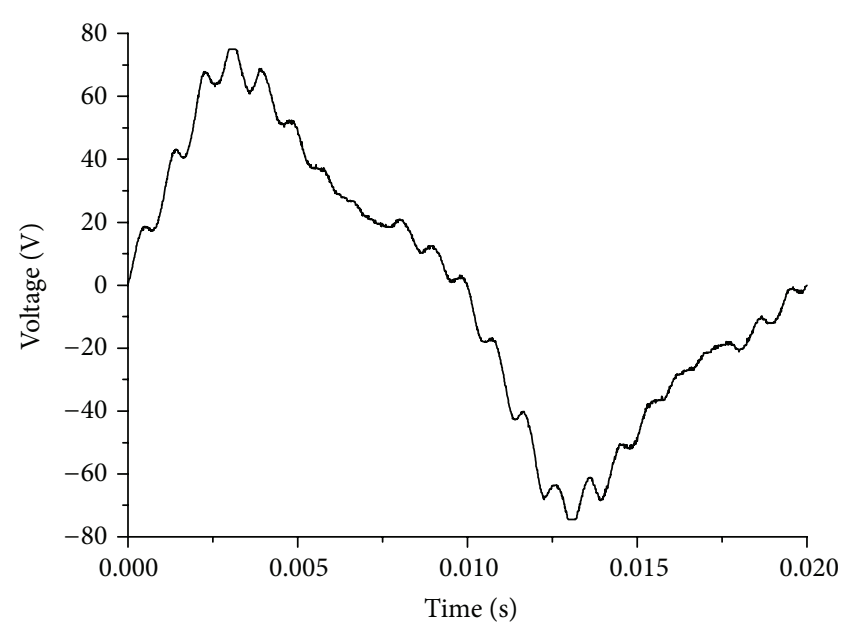

(b) Measured result

FIGURE 4: Comparison of line voltage between open-circuit and short-circuit phases after short circuit of two-phase AC windings reached steady state.

TABLE 2: Comparison of calculated and measured results after short circuit of two-phase AC windings reached steady state.

\begin{tabular}{lcccc}
\hline & $\begin{array}{c}\text { Field } \\
\text { current } \\
\text { (A) }\end{array}$ & $\begin{array}{c}\text { Short- } \\
\text { circuit } \\
\text { current } \\
\text { (A) }\end{array}$ & $\begin{array}{c}\text { Phase voltage } \\
\text { of open phase } \\
\text { (V) }\end{array}$ & $\begin{array}{c}\text { Line voltage } \\
\text { between } \\
\text { open-circuit } \\
\text { and } \\
\text { short-circuit } \\
\text { phases (V) }\end{array}$ \\
\hline Measured & 1.337 & 25.0 & 31.8 & 46.1 \\
Calculated & 1.337 & 24.5 & 32.6 & 46.3 \\
Error & - & $2.04 \%$ & $2.52 \%$ & $0.43 \%$ \\
\hline
\end{tabular}

topology of circuit is not changed, the effect is evident that the speed of ICCG method is nearly $30 \%$ greater than that of Gauss elimination method.

\section{Convergence of ICCG Method}

When ICCG is used to simulate the variable topology structure circuit, one difficulty occurs. Once the state of any diode changes from on to off, the connection transformation matrix is modified and then the simulation may not be convergent and process cannot proceed. It is interesting that this difficulty does not occur for Gauss elimination method even with variable topology circuit.

In order to keep the advantage of shorter simulation time of ICCG method and achieve the numerical convergence, a straightforward approach, by combining the ICCG method and Gauss elimination method, is proposed here.

The ICCG method is used to the solve equations in the simulation process, except just one simulation step after any diode switches off. Once the topology structure of circuit changes, the Gauss elimination method is adopted to simulate 


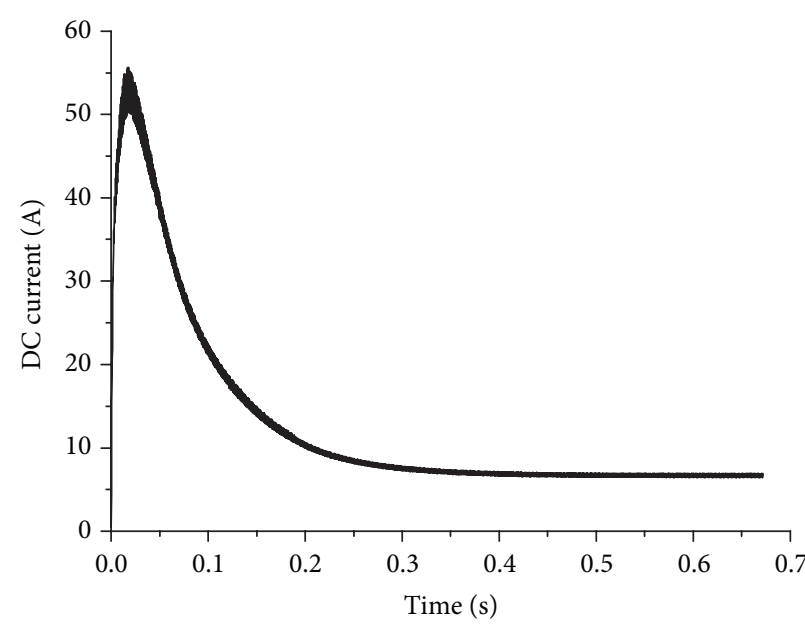

(a) Calculated DC current

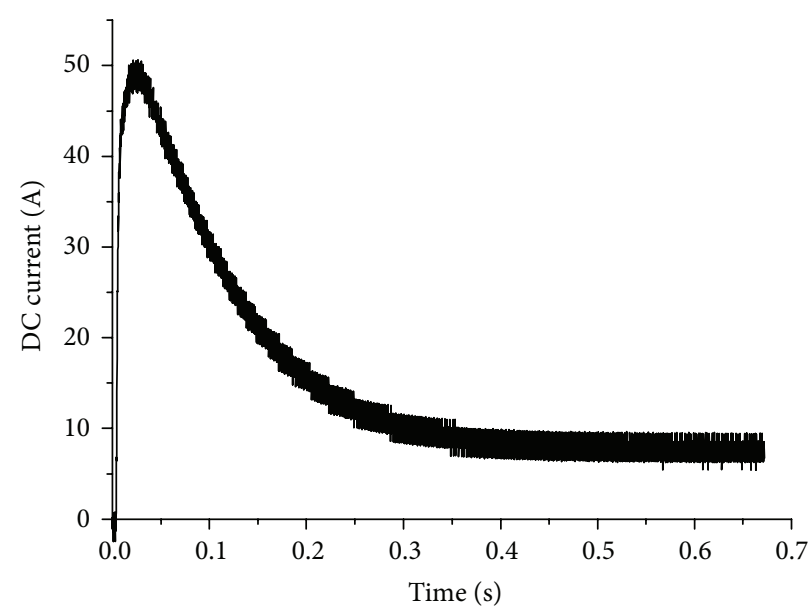

(b) Measured DC current

FIgURE 5: Comparison of DC current with sudden DC side short circuit.

forward just one step; after that, ICCG method can be used immediately. By this way, the numerical instability can be eliminated.

\section{Comparison of Simulation and Experiment}

At last, the validation of this simple approach is verified by the comparison of performance simulation and experiments. The experimental verification of the technique described in this paper was accomplished using a model generator (design data as Appendix). Figure 3(a) shows the cross-section view and mesh, and Figure $3(\mathrm{~b})$ is the flux density picture. A series of tests and simulations were carried out and compared under different operating conditions. Table 2 gives the comparison of calculated and measured results after short circuit of twophase AC windings reached steady state, while Figure 4 shows the comparison of line voltage between open-circuit and short-circuit phases. Figure 5 shows the comparison of calculated and measured DC currents when DC side is suddenly short-circuited, which means that the topology of system always changes.

It can be seen from these figures that the calculated waveforms coincide with those of experiments, which also verifies the effectiveness of the straightforward ICCG convergence method proposed in this paper.

\section{Conclusions}

Multiloop model and FE model of electric machine are combined to simulate electric machine and power electronics systems, where the magnetic nonlinearity of iron core and the circuit nonlinearity caused by power electronics devices are considered in detail.

In order to increase simulation speed, a straightforward approach, by combining the ICCG method and Gauss elimination method, is proposed. The proposed method can keep the advantage of ICCG method and achieve the numerical convergence for variable topology circuit simulation at the same time.

\section{Appendix}

Parameters of the Model Generator. Stator inside diameter is $250 \mathrm{~mm}$, slot number is 48 , pole pair number is 2 , damper bar number per pole is 7 , maximum air-gap is $1.5 \mathrm{~mm}$, minimum air-gap is $1 \mathrm{~mm}$, and pole arc coefficient is 0.72 .

(1) AC Winding. Rated voltage is $390 \mathrm{~V}$, rated power is $15 \mathrm{~kW}$, rated current is $27.8 \mathrm{~A}$, power factor is 0.8 , rated frequency is $50 \mathrm{~Hz}$, pitch is 10 , turns of phase winding are 72 , and number of slots per pole per phase is 4 .

(2) DC Winding. Rated voltage is $510 \mathrm{~V}$, rated power is $3.3 \mathrm{~kW}$, rated current is $6.5 \mathrm{~A}$, pitch is 10 , turns of phase winding are 64 , and number of slots per pole per phase is 1 .

\section{Conflict of Interests}

The authors declare that there is no conflict of interests regarding the publication of this paper.

\section{Acknowledgment}

The authors appreciate the support of Research Project of Tsinghua University (no. 20111081032).

\section{References}

[1] S. L. Ho, S. Niu, and W. N. Fu, "Transient analysis of a magnetic gear integrated brushless permanent magnet machine using circuit-field-motion coupled time-stepping finite element method," IEEE Transactions on Magnetics, vol. 46, no. 6, pp. 2074-2077, 2010.

[2] K. Yamazaki and Y. Kanou, "Shape optimization of rotating machines using time-stepping adaptive finite element method," IEEE Transactions on Magnetics, vol. 46, no. 8, pp. 3113-3116, 2010.

[3] N. Stranges, "Calculation of the starting performance of solid pole synchronous motors by the time-stepping finite element method," in Proceedings of the IEEE Power and Energy Society 
General Meeting: Conversion and Delivery of Electrical Energy in the 21st Century (PES '08), pp. 1-4, Pittsburgh, Pa, USA, July 2008.

[4] B. M. Ebrahimi, J. Faiz, M. Javan-Roshtkhari, and A. Z. Nejhad, "Static eccentricity fault diagnosis in permanent magnet synchronous motor using time stepping finite element method," IEEE Transactions on Magnetics, vol. 44, no. 11, pp. 4297-4300, 2008.

[5] S. L. Ho, S. Niu, and W. N. Fu, "Reduction of numerical errors of time-stepping finite element analysis for dynamic simulation of electric machines," IEEE Transactions on Applied Superconductivity, vol. 20, no. 3, pp. 1864-1868, 2010.

[6] K. Yamazaki and Y. Kanou, "Speedup of nonlinear iterative scheme by utilizing convergence characteristics of NewtonRaphson method and ICCG method," in Proceedings of the 12th Biennial IEEE Conference on Electromagnetic Field Computation, p. 467, Miami, Fla, USA, 2010.

[7] A. Kameari, "Improvement of ICCG convergence for thin elements in magnetic field analyses using the finite-element method," IEEE Transactions on Magnetics, vol. 44, no. 6, pp. 1178-1181, 2008.

[8] H. Igarashi and T. Honma, "On convergence of ICCG applied to finite-element equation for quasi-static fields," IEEE Transactions on Magnetics, vol. 38, no. 2, pp. 565-568, 2002.

[9] P. W. Franklin, "A theoretical study of the three phase salient pole type generator with simultaneous AC and bridge rectified DC output, part I and II," IEEE Transactions on Power Apparatus and Systems, vol. 92, no. 2, pp. 543-557, 1973.

[10] R. F. Schiferl and C. M. Ong, "Six phase synchronous machine with AC And DC stator connections, Part I and Part II," IEEE Transactions on Power Apparatus and Systems, vol. 102, no. 8, pp. 2694-2701, 1983.

[11] S. M. Wang, X. H. Wang, Y. X. Li, P. S. Su, W. M. Ma, and G. F. Zhang, "Steady-state performance of synchronous generators with AC and DC stator connections considering saturation," IEEE Transactions on Energy Conversion, vol. 17, no. 2, pp. 176$182,2002$. 


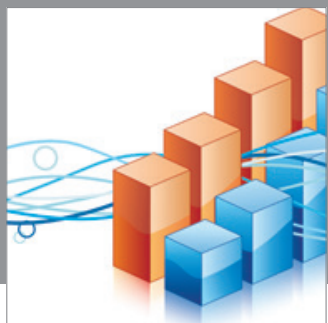

Advances in

Operations Research

mansans

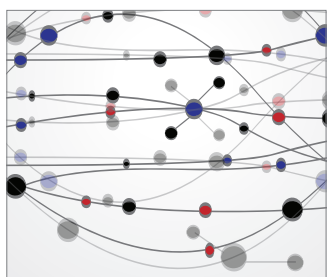

The Scientific World Journal
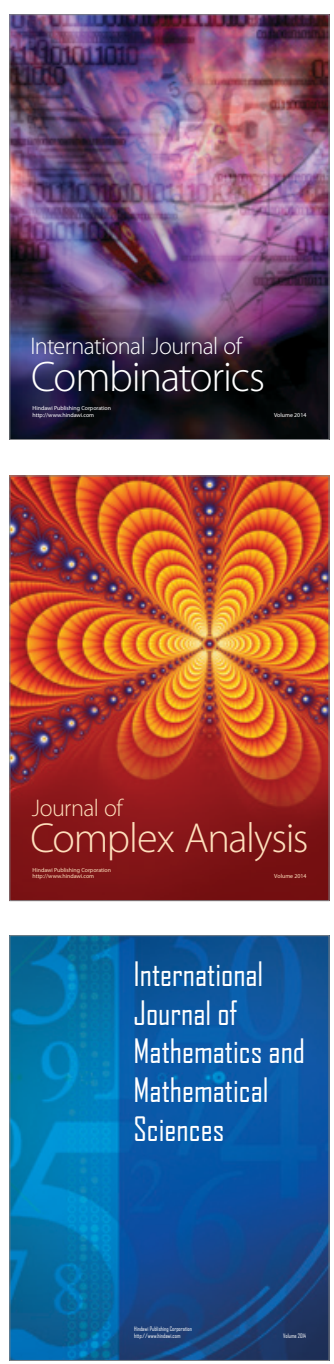
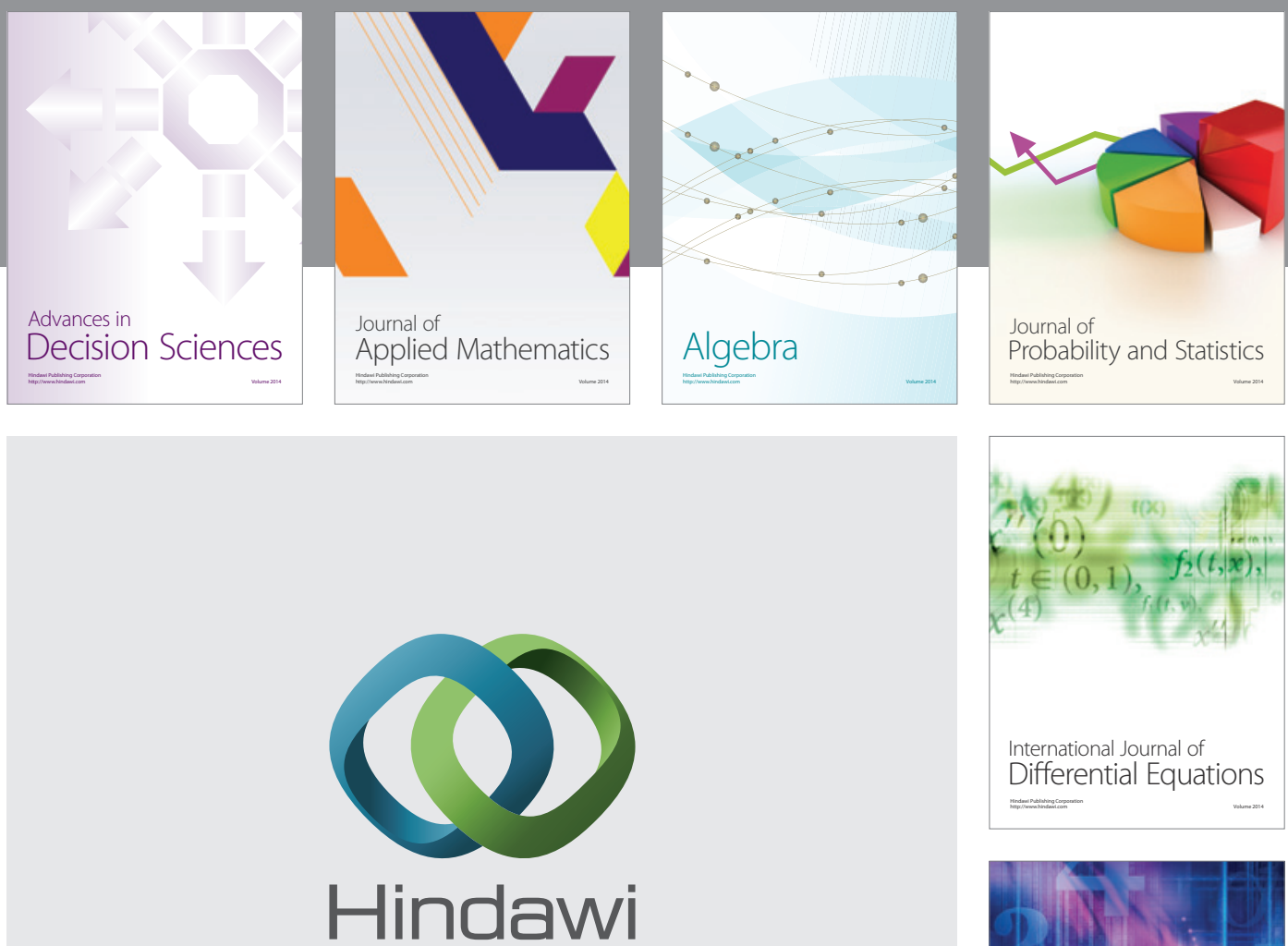

Submit your manuscripts at http://www.hindawi.com
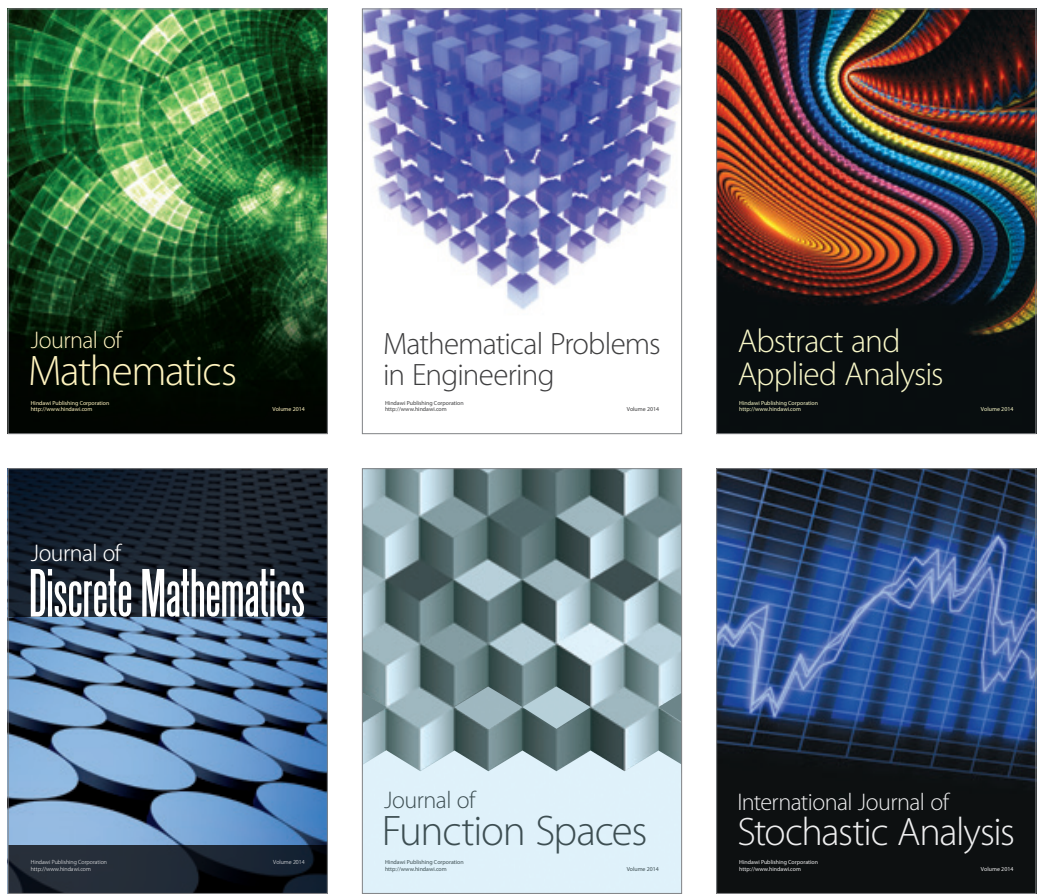

Journal of

Function Spaces

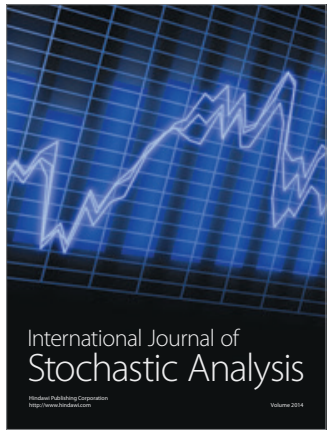

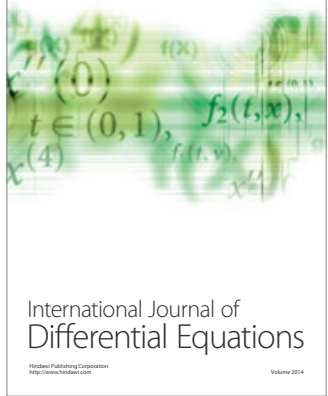
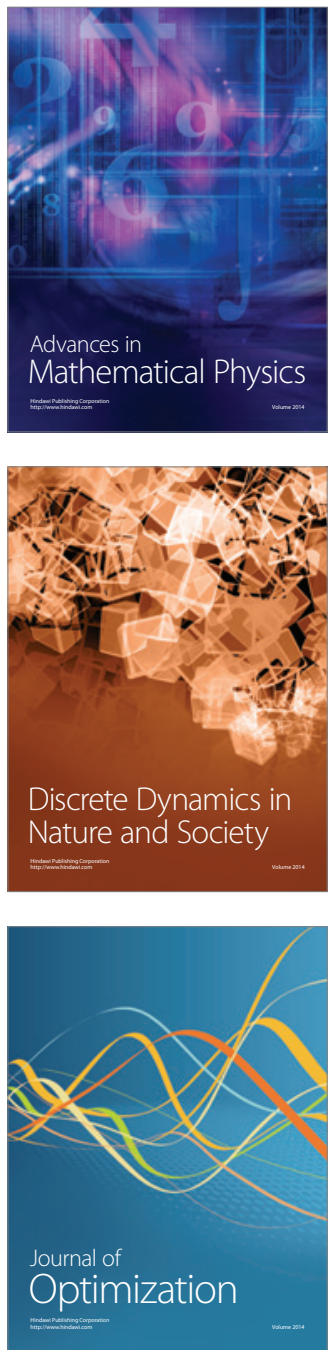